que motivam a proibição da vingança privada naquele, e o revestimento de formalidades certos atos, nestes. Para descobrir um novo enfoque possibilitando vislumbrar a natureza substitutiva da jurisdição graciosa e penal, veja nosso trabalho Chiovenda, jurisdição voluntária e processo pe nal publicado na Revista de Processo, RT, v. 81, janeiro-marco de 1996, p. 233-239, bem como Revis ta Trabalho \& Processo ou Trabalho e Doutrina, Sa-

17 Gian Antonio Micheli, Per una revisione

di giurisdizione voluntaria Rivista 1947 v I traduzido para o espanhol e re publicad. . . p. 31 , nos Estudios de derecho procesal civil, v. IV 1970 8 J. J. Calmon de Passos Da jurisdiçäo 1957, p. 18 19 Marco Tullio Zanzucchi Diritto processuale civile

20 Por isto que quando das polèmicas em torno do SF os juizes que eram mutuários do sistema conside- ravam-se suspeitos para decidir tais causas pois, como mutuarios, possuiam interesse (ainda que re motol de que prevalecessem as teses que reduziam as prestações.

21 Maria Sylvia Zanella di Pietro, Discricionariedade Administrativa na Constituição Federal de 1988, tese de livre-docência na USP, aprovada com grau 10 pelos 5 membros da banca examinadora composta, entre outros, por José Cretella Jr., e publicada pela Atlas em 1991.

22 Cesar Viterbo Matos Santolim, A responsabilidade Civil do Estado, trabalho apresentado no Mestrado em Direito da Ufrgs, e publicado na Revista Estudos 55, p. 45.54 Fac. de Direito da Unisinos, v. 22, $\mathrm{n}^{6}$ 5. p. 45.54, conlira tambèm Luiz R. Nuñes Padilla, Responsabildade Civil do Estado por Ato Jurisdi(COAD) 1993, p.

\section{A Constituição de 1988 e a Judicialização da Política}

\author{
Manoel GonÇalves Ferreira Filho
}

Professor Titular de Direito Constitucional da Faculdade de Direito da USP.

Doutor em Direito pela Universidade de Paris.

Professor Visitante da Universidade de Aix-en-Provence (França).

Membro da Comissão Executiva da

Associação Internacional de Direito Constitucional

Presidente do Instituto "Pimenta Bueno"

(Associação Brasileira dos Constitucionalistas)
1. Tanto no Brasil como no estrangeiro preocupam-se juristas e politólogos com o fenômeno da judicialização da politica. Aqui, já é ele. há certo tempo, assunto de debate tanto no meio jurídico quanto no politico ${ }^{1}$

Lá fora, o interesse pelo tema levou à publicação de um número especial da Internationa Political Science Review, intitulado "The judicialization of politics"

\section{I - O CONCEITO DE JUDICIALIZAÇÃO}

2. Entende-se por judicializacão da politica a tendência a atribuir, ou submeter, aos tribunais judiciários a decisão de mérito a respeito de açōes administrativas ou normas obrigatórias. Ou seja, decisões "politicas", porque concernentes a 0 interesse da comunidade.

Talvez melhor fosse falar em judicialização do político, pois a förmula judicialização da politica traz a impressão errônea de que a disputa política é que é judicializada, quando é a ação governamental que cai nas mãos dos juizes. Entretanto, a experiência mostra que não adianta lutar contra expressōes difundidas, mormente quando elas soam bem. É o caso da expressão empregada.

Em outras palavras, consiste a judicializa cao em atribuir ao Judiciário decisōes que, no termos da doutrina clássica da separação dos poderes, incumbiriam ao Executivo ou ao Legislativo. Decisões estas de caráter político, eis que afetam o destino da comunidade (a polis), ou importam em orientar em direção a objetivos determinados a máquina governamental, em decorrência de uma visão do bem comum.

Num sentido mais fraco, todavia, a expressão é empregada para designar a adoção de procedimentos próximos aos típicos da Justiça para a preparação da tomada de decisões por órgãos administrativos ou legislativos. Assim, nos Parlamentos, os hearings, em que se ouvem interessados na decisão a ser tomada, nas administrações, o convite aos interessados para que se manifestem, como se faz às vezes no caso de operaçōes de renovação urbana, de desapropriações para grandes obras, de obras que possam afetar o meio ambiente, etc. Não é esta judicialização, entretanto, que nos preocupa neste trabalho.

\section{II - A JUDICIALIZAÇ̃̃O NO ESTRANGEIRO}

3. Nos Estados Unidos, a judicialização no sentido forte vem de longe. Talvez por isso seja esse pais o lugar em que aparece mais avança$\mathrm{da}^{3}$

Está ela intimamente ligada à judicial review, ou melhor, um alargamento do escopo da mesma. De fato, a Suprema Corte, de 1954 para cá, embora com menor intensidade nos últimos anos, vem, ao fulminar atos ou normas por inconstitucionalidade, afirmando padrões positivos que devem ser obrigatoriamente seguidos. 
Ora, estes padrões são, conforme o caso, impositivos para o legislador, ou para a administração pública.

0 marco inicial dessa nova postura é a famosa decisão Brown v. Board of Education 4 que impôs a dessegregação das escolas. $\mathrm{E}$ a determinou com "all deliberate speed".

Na verdade, como aponta Martin Shapiro, a Suprema Corte, sob a direção de Earl Warren veio a definir o procedimento policial em relação a suspeitos ou acusados, um novo direito relativamente à obscenidade, a reforma do sistema de eleição dos deputados estaduais e federais, etc. Sob Burger, quanto ao aborto, a pen de morte e as condições das prisōes, etc. ${ }^{5}$

4. O fenômeno também é patente na Alema$n a^{6}$. A Corte Constitucional não se tem contentado, na função de controle de constitucionalidade, com a alternativa de, ou nulificar a lei, ou considerá-la consentânea com a Lei Magna. Assim, construiu a técnica da "interpreta ção de acordo com a Constituição" (verfassungskonforme Interpretation), pela qual entend constitucional uma lei, desde que ela seja inter pretada de um determinado modo que fixa. Igualmente, pode ser considerada como a criasó condenando a omissão do legislador como assumindo, ou pelo menos dispondo-se a assumir o papel deste, escoado um prazo por ela própria fixada. Isto, afora a adoção de critérios como o de proporcionalidade, para o crivo das normas legais que envolvem sempre um certo grau de subjetividade.

Por outro lado, sempre por meio do controle de constitucionalidade, tem afeiçoado a seus critérios a legislação eleitoral. Por exemplo, ao fixar em $0,5 \%$ dos segundos votos (os partidários) o limite minimo, para que o partido tenha direito a reembolsos de despesas eleitorais e não $2,5 \%$ como estava na lei. Ou ao julgar que os limites máximos para as contribuiçoes para despesas eleitorais seriam inconstitucionais se fixados em proporção aos resultados eleitorais ou à riqueza do contribuinte, mas sendo válidas as contribuiçōes de até $100.000 \mathrm{DM}$ por parte de individuos ou firmas. Nessas decisões pode manifestar-se o bom senso, mas é dificil vê-las justificadas por critérios constitucionais objetivamente determinados.
5. E o mesmo fenômeno se pode apontar na Grã-Bretanha, na Suécia, na Holanda ${ }^{7}$, etc.

\section{III - A JUDICIALIZZAÇ̃̃o NO BRASIL ANTES} DA CONSTITUIÇÃO EM VIGOR

6. Antes da Constituição de 1988, era negligenciável a judicialização da política no Brasil embora nalguns pontos ela já aparecesse. Não por obra do Supremo Tribunal Federal que, no tocante a controle de constitucionalidade, sempre assumira uma posição de contenção, mas devido à atuação de juizes e tribunais estaduais.

Na verdade, foi na ampliação jurisprudencial do âmbito da ação popular que a judicializacão primeiro se manifestou. Isto se deu a partir dos anos setenta, quiçá em reacão contra a fatta de controle politico da atuacão governamental em razão do chamado regime militar.

Uma interpretaçāo larga de "patrimônio público" ensejou que os juizes se habilitassem ao controle de atos concernentes ao meio ambiente, à herança histórica, às paisagens e à cultura, ao mesmo tempo que, por uma interpretacào larga de "lesividade", ousaram algun tificá-la a conveniência, necessidade adequação, etc.

Por outro lado, como essa ação comporta liminar suspensiva do ato impugnado, e cai ela na competência do juiz singular - mais moço e mais ousado - 0 Judiciário, e por intermédio de seus juizes mais jovens, passou a interferir nas opçóes governamentais, proibindo construções, demoliçōes, enchimento de represas, etc ${ }^{8}$.

A seu turno, às vésperas da nova Constituição um novo instituto - a ação civil pública trouxe uma importante contribuição para a judicialização. Esta ação, criada, em 1985, pela Lei no 7.347 , tem como escopo fazer valer a responsabilidade por danos causados ao meio ambiente, ao consumidor, a bens e direllos de valor artístico, estético, histórico, turistico e paisagistico, atribuindo-se a legitimidade ativa para ela ao Ministério Público.

Ora, freqüentemente é o próprio Estado, por suas projeções, as autarquias, as empresas públicas, as sociedades de economia mista, o acusado por esses danos. Assim, por meio da ação civil pública - pode-se dizê-lo - è a própria atuação do Estado que é contestada. E num terreno em que não podem existir padrōes legais definidos, prevalecendo apreciacões de oportunidade e conveniência não raro subjetivas.

Se essa lei pôs o Ministério Público na primeira linha do combate a erros e abusos do Governo - politizando-o - evidentemente ela obriga o juiz, em muitos casos, a assumir a postura de administrador, devendo sopesar aspectos de conveniência, de oportunidade, a fim de decidir o mérito do pleito.

\section{IV - A CONSTTTUUIÇão DE 1988 E A JUDICIALIZAÇ̃̃o DA POLÍ́TICA}

7. Incontestavelmente, porém, foi a Constituição de 1988 que, consciente ou inconscientemente, determinou ampla e visivel judicialização da politica. $\mathrm{E}$ isto não só, diretamente, em razão de institutos que adotou, ou do caráter de seu texto, como por haver ampliado ao alcance de outros, criando, ademais, indiretamente um ambiente propicio ao uso de instrumentos há muito consagrados, como o mandato de seguranca, num sentido de interferência com a politica de governo (reputada inadequada, ou injusta).

\section{A - A Contribuição do Texto}

8. O próprio estilo (ou sua falta) de redação da Carta de 1988 provoca essa judicialização.

Por um lado, o texto não segue nem de longe os padrōes da terminologia juridica. Leva 0 intérprete, portanto, o juiz, a ter de adivinhar, e aí cada um lê o que gostaria de ler. Contém absurdos, como a fixação de um máximo de juros numa economia como a brasileira, sugerindo com isso que não se leiam alguns preceitos. Aprecia fórmulas genéricas, de conteúdo indeterminado, como "sadia qualidade de vida", "recursos ambientais necessários a seu bem-estar e necessários a sua reprodução fisica e cultural", "exploração que favoreça o bem-estar dos proprietários e dos trabalhadores", "moralidade administrativa", etc. E assim força a apreciações valorativas que evidentemente envolvem um grande subjetivismo.

Ademais, como técnica de conciliação, Constituinte teve o mau vezo de combinar no mesmo dispositivo o que queria a esquerda e o que queria a direita, por meio de redaçōes arrevezadas, obscuras, ou por meio da cláusula dilatória "nos termos da lei" - que cada lado podia apresentar como vitoria sua. $\mathrm{E}$ com isto deixando ao Judiciário, por sua conta e risco, darlhe sentido e suportar a inexorável crítica de um setor da opiniazo. Que tal dirimir entre a expropriação para reforma agrária do imóvel que "não esteja cumprindo sua função social" quando esta não pode colher "a propriedade produtiva"?

B - O Controle de Constitucionalidade

9. Vejam-se, por outro lado, as inovaçōes ou ampliaçōes de institutos já presentes no direito anterior.

O primeiro ponto a salientar concerne ao controle de constitucionalidade, por meio da ação direta de inconstitucionalidade.

Observe-se, desde logo, que na repercussão politica há uma imensa diferença entre o controle incidental e o controle direto. Naquele, com a sutileza posta por Marshall, o juiz não é levado a um confronto direto com o legislador. Ele afasta a aplicação da norma (inconstitucional), no exercício da função típica de determinar a regra aplicável a um caso concreto. Ele não a declara nula, inválida, isto são decorrências doutrinárias, nem lhe suspende a execução erga omnes, esta é uma atribuição do Senado, poder politico e integrante do Legislativo. Ademais, vindo caso a caso o seu impacto é suave sobre a pele do parlamentar. $\mathrm{E}$ o mais das vezes há uma demora entre a promulgação da lei e a sua não aplicação, longa suficientemente para que o sentido de paternidade parlamentar se tenha acalmado.

Na ação direta, não, ainda mais com a possibilidade da liminar. 0 juiz julga a lei e quando dá a inconstitucionalidade reprova 0 legislador. Freqüentemente pouco depois da edição da regra. Se essa ação tem inegáveis vantagens quanto à segurança jurídica, apresenta a desvantagem de fazer evidentemente um conflito entre poderes. Um a invocar a soberania democrática, ou tro o império da Constituição.

A ação direta de inconstitucionalidade já existia antes da promulgação da Carta atual, mas só podia propô-la o Procurador Geral da República. Isto indubitavelmente representava um freio e uma seleção das demandas de inconsti- 
tucionalidade, por motivos perfeitamente óbvi-

Generosamente, porém, a nova Carta estendeu a legitimidade para essa ação não só a inúmeras autoridades, mas igualmente a partidos politicos, a confederações sindicais ou a entidades de classe de âmbito nacional, etc.

$O$ resultado foi, como se tem diante dos olhos, não apenas a multiplicação dessas ações, mas também a multiplicação de conflitos entre Supremo Tribunal Federal e o legislador, mormente o legislador de fato, o Executivo, inclusive com suas medidas provisórias que ignoram - às vezes parece de propósito - as normas constitucionais.

10. Se isso não bastasse a Constituição acolheu a ação direta de inconstitucionalidade por omissão (no cumprimento de norma constitucional). Sem dúvida, essa cópia da Lei Magna Portuguesa de 1976 se situa bem dentro do espirito da constituição-dirigente à moda de Canotilho. Com efeito, esta preordena num rumo definido - no original o estabelecimento do sociaismo e depois do comunismo - a atuação dos sucessivos governos, por meio da possibilidade de impor a estes, por via judicial, a efetivação dos programas, e evidentemente de normas prodos programáticas.

gramáticas. faria do Judiciário um legislador. De fato, o poder de declarar "a inconstitucionalidade por omissão de medida para tornar efetiva norma constitucional" deveria ter como consectário poder de regular a matéria a respeito da qual 0 Congresso Nacional se omitiu. Entretanto, embora houvesse na Constituinte quem o desejasse, o texto adotado não foi tão longe - apenas determinou que, reconhecida a omissão, será dada ciência da mesma ao Congresso Nacional.

De qualquer modo, esta "ciência" importa numa censura, ainda que com as famosas luvas de pelica, ao Congresso.

11. Aproxime-se desta ação o mandado de injunção. Este, que não tem precedente nacio nal ou estrangeiro, a não ser a própria inconstitucionalidade por omissão, visa a tornar possivel o exercício de "direitos e liberdades constitucionais", inviabilizado por falta de norma regulamentadora. Sua decorrência lógica seria 0 suprimento da lacuna, isto é, a edição da norma regulamentadora.
Houve, na Constituinte, quem o quisesse Contudo, como a idéia provocasse resistência chegou-se a um acordo: inseriu-se no texto somente a hipótese em que caberia o instituto, deixou-se o mandamento, a conseqüência ao Judiciário... E grande parte da doutrina, vigente a Constituição, quis que o Supremo levasse às últimas esse novel instituto incompleto, assumisse a postura de legislador. Ele não o fez equanta critica desabou, e ainda desaba, sobre

De qualquer modo, aqui, de novo, a Constituição faz o Judiciário de censor do Legislativo e se não o traz à légiferação, o deixa no limiar disto

12. Some-se isto a contribuição da Emenda Constitucional no $3 / 93$, a ação direta de constitucionalid visa a declarar constitucional lei ou ato normativo federal. Isto é à primeira vista surpreendente. De fato, em termos doutrinários, a constitucionalidade é presumida.

O intuito, porém, que levou à instituição é claro. Por um lado, é evitar longas controvérsias sobre a constitucionalidade ou inconstitucionalidade, mormente de leis ou medidas provisórias. Por outro, é obter do Supremo, por meio de uma "ação" sem contraditório - se de ação se possa chamar um processo sem contestação - uma como que "sanção" judicial da norma.

Tal posição revoluciona o papel deste Tribunal como controlador de constitucionalidade, aproxima-o do Conselho Constitucional francês que examina a constitucionalidade da lei, antes de entrar esta em vigor (podendo sugerir alterações nelas que a tornem compativel com a Le Magna).

E não se olvide que as decisões definitivas de mérito em açōes de constitucionalidade têm "eficácia contra mente aos deme ao Poder Executivo".

\section{C - 0 Controle da Administração}

13. No que tange à judicialização da politica no plano administrativo, a Constituição já encontrou os dois grandes instrumentos pelos quais ela hoje ocorre a ação popular e a ação civil pública. Deu-lhes, porem, um campo mais amplo, pois consagra na sua letra a extensão jurisprudencial daquela, e quanto a esta the concede o que a lei lhe vedava, ou seja, a interveniência em questões referentes ao patrimônio público. E sempre com a possibilidade das limipúblico.

Ninguém contestará os aspectos positivos de uma ampliação do controle sobre a administração pública. Mas a que consagra a Constituição no ponto em exame, tem alguns inconveniente que seria necessário corrigir.

A ação popular e a acão civil pública têm sido freqüentemente usadas como arma politica. Elas são exigidas pelas oposições contra governantes, sobretudo contra os que não são "politicamente corretos" ao ver da imprensa, da intelectualidade, e da classe média (alta) de que fazem parte juizes e membros do Ministério Público. Sua proposição é acolhida com aplausos por parte da imprensa de oposição, dá o famoso minuto de celeridade a quem as propôs, inclusive os membros do Ministerio Público, e sua acolhida, especialmente numa liminar dada de chofre, ao juiz. Ademais, como as questōes que provocam essas decisões são "noticia", freqüentemente são elas tomadas perante as câmaras da televisão (ou sob a pressão delas). Mas este o problema da "videodemocracia".

Ora, o juiz que decide essas ações em primeira instância, não raro ingresșou há pouco na carreira, é inexperiente. Năo sabe resistir pressão dos meios de comunicação, por isso às vezes cede, curvando-se ao que é politicamen correto.

\section{D - O Controle das Eleições}

14. Igualmente, a Constituição já encontrou a Justiça Eleitoral, mas, com muito boas intencões, lhe alargou a esfera.

De fato, institui uma ação de impugnação de mandato, fundada em "abuso de poder econômico, corrupção ou fraude". Pondo-se de lado esta última hipótese, as duas outras obrigam a Justiça a emergir num terreno movediço que é o do financiamento eleitoral.

O ponto mais delicado, porem, concerne ao verdadeiro poder normativo que tem esta Justica no que tange às eleições. E ela que; por meio de "instruções", regulamenta o processo eleito- ral. Nisto, incontestavelmente ocorre uma judicialização da politica. O "legislador" em pontos importantes é o Judiciário.

\section{E - Razões da Judicialização}

15. Cabe indagar o por quê desse fenômeno de judicialização.

Tendo em mente 0 caso norte-americano, Shapiro aponta que isso se desenvolveu em reação à "política partidária eleitoralista" ("partsan electoral politics") e à "pressão dos grupos de interesse" ("interest group lobbying"). E comenda: "Uma corte, não eleita, 'independente' e 'neutra' dá um passo adiante para corrigir uma 'falha' ou a 'patologia' do processo democrático. A substituição do 'judicial policy making' ao 'legislative/executive policy making' é legitimado em parte pela invocação dos direitos da minoria contra a vontade da maioria e em parte pelo argumento de que em algumas raras instânci gumento de que "is not self-correcting") sem a intervenção judicial"8.

16. No Brasil, como já apontei no artigo mencionado, o apelo à judicialização tem algumas razões fáceis de identificar

Embora não haja - que se saiba - qualquer doutrina por detrás disto, o Judiciário goza de uma confiabilidade que os Poderes "politicos" Legislativo e Executivo perderam. Estes são olhados com desconfiança pela opinião pública, a alimentada pelos meios de comunicação de massa.

A presunção de que os atos destes dois Poderes sejam legitimos e visem ao interesse geral, mantém-se no plano juridico-formal. Do ângulo da opinião pública, não. São eles compostos de "politicos" e estes são objeto de escárnio, pois, todos duvidam trabalhem para o interesse geral.

Na verdade, o próprio legislador constituinte sssumiu essa posição de descrença. A inconstitucionalidade por omissão, o mandato de injunção, as minudências de caráter infraconstitucional do texto - bem como os inúmeros prazos para a edição de leis, afora a preordenação do conteúdo destas, para vigorar até que venha a lei regulamentadora, que estabelece 0 Ato das Disposicom Constitucionais Transitorias - de- 
monstram suficientemente que o constituinte não acreditava no trabalho do legislador ordinário.

Este descrédito não colhe o juiz. No fundo, é este uma personalidade mais proxima dos bem pensantes que fazem a opinião pública. $E$ mais aceitável para essa burguesia "esclarecida". É formado a nivel superior, selecionado por meio de concurso, adstrito à independência e à imparcialidade, por isso - entende essa faixa da sociedade - é melhor que a ele seja dada a decisão em matérias importantes - como as grandes decisōes politicas - do que aos "politicos" - vistos como ignorantes, corruptos, interesseiros, demagógicos..

Ainda mais que o processo judicial assegura a manifestação de opiniões diversas (o contraditório), e leva a decisões que são reexaminadas em nivel superior. Por isso, supõe-se que essas decisões sejam corretas e objetivamente tomadas.

Alèm disso, hả um fator social. Os juizes pertencem, no Brasil, à classe média alta, "politicamente correta". Ora, esta classe, a formadora da opinião püblica, descrente nos políticos (que considera mais ou menos populistas) evidentemente sente maior confiança nos seus..

Enfim, muito tem contribuido para a judicialização nos últimos anos o ativismo de jovens juizes. Estes não têm hesitado, no controle de constitucionalidade difuso, em se contrapor ao Governo, anulando freqüentemente os seus atos. Reação a isto é exatamente a instituição, já comentada, da ação direta de constitucionalidade, claramente destinada a coibir a atuação critica dos escalōes inferiores da magistratura. Isto, concentrando nas mãos do Supremo a apreciação da constitucionalidade de leis potencialmente controversas, e, mais, impondo a sujeição de todos os outros juizos à decisão tomada por essa Corte.

18. Mas é preciso convir que os magistrados não estão, de modo geral, preparados para o tipo de decisões que deles reclama a judicialização, principalmente quando esta os leva a substituir 0 administrador. $O$ tino administrativo não é dos que se adquirem no estudo dos livros mas exige experiência que, se às vezes 0 administrador político não possui, a sua assessoria de funcionários experimentados, não raro tem. Mesmo a redação de leis tem uma técnica propria que a maioria dos juristas - habituados a aplicá-las - não dominam.

Por outro lado, a decisão politica reclama freqüentemente a ponderação de inúmeros aspectos e interesses contraditórios. $\hat{\mathrm{E}}$ muitas vezes uma escolha entre males necessários, ou entre valores prestigiados, mas que se opõem no caso concreto.

Isto bem se vê nas momentosas questões ambientais, ou assemelhadas: energia nuclear com os vazamentos), energia hidráulica (com as imensas inundacooes e a destruição ou ou até a extinção de espécies animais e vegetais), energia da combustão (do petróleo, da madeira, do carvão e a poluição)? Ou falta de energia (com black-out nas cidades, paralisia do desenvolvimento industrial, falta de empregos ou mesmo desemprego)? Etc., etc. Assim, ela não se ajusta o jogo de soma nula que decorre da decisão judicial: certo (licito), errado (ilicito). Nem deflui pura e simplesmente de paradigmas legais.

Ora, o juiz está habituado a essa separação radical, preparado que foi para separar o legal do ilegal. Em razão disto, costuma ter uma visão maniqueista das coisas. Ignora que a opcão do administrador sopesa alternativas complexas, as vezes entre varios males. Assim, fulmina xas, às vezes entre varios males. Assim, fulmina muitas vezes o que teve de ser decidido de pressa e envolve uma escolha que é... politica em sua natureza, mas que não è a politica que escolheria (mas não foi ele quem o povo elegeu). Acostumado a exigir o "certo" e a condenar o "errado", impõe, como se deu num caso clássico, sejam salvos os cervos do pantanal (espécie em extinção) antes de inundada uma barragem. Com isto, não só retardando uma obra de grande interesse geral, mas provocando um dispêndio que daria para construir habitaçōes adequadas para toda uma (numerosa) comunidade, ou qualquer outra coisa que beneficiasse a populaçāo carente.

Enfim, cumpre não esquecer a questão da legitimidade. $O$ juiz não é escolhido pelo povo (nem o deve ser), não representa o povo senão em termos metafóricos. Nem é desejável que se politize.

\section{VI - A POLITIZAÇÃo DA JUSTIÇA}

19. A judicialização da politica tem como contrapartida inexorável a politização da justi- ç. $O$ aspecto bem visivel disto está no fato de que hoje há magistrados que notoriamente guiam seus votos pela "opinião pública", o que guiam seus voto

nicação de massa.

Estes "profetizam" os votos dos membros de uma Corte - o Supremo Tribunal Federal, po exemplo - analisando posições jurídicas como se fossem opcōes ideológicas ou partidárias. nisto são ajudados por membros do Judiciário que, em off, vazam informaçōes, antecipam votos, movidos pelo desejo ou de agradar ou de tos, movidos pelo desejo ou de agradar ou de justific

20. A politização da justiça é desejada por muitos no Brasil atual.

De um lado, são os que batalham para a adoção do "controle externo" do Judiciário. É claro ção do "c que o pretexto é a necessidade de punir a incúria de magistrados, ou de reprimir seus eventuais abusos. Entretanto, a verdadeira finalidade é outra. De outro, os que postulam um direito "alternativo", versão ideologizada e simplista do "Freirecht". Neste caso, o pretexto é servir aos carentes.

Em ambos os casos, trata-se de politizar 0 sentido no sentido de impor às decisōes judiciais um padrão que não é 0 da lei objetivamente considerada nem na da justiça intemporalmente encarada, mas "partidária". Seja este o partidarismo de uma corrente politica, seja ele o posicionamento "politicamente correto"13.

$\mathrm{Em}$ ambos os casos, em favor disto invoca-se a democracia, a vontade popular.

Entretanto, a democracia moderna - a democracia representativa - é uma forma de governo misto, de acordo com a longa tradição de que a melhor forma não é qualquer das puras, mas a que combine o lado positivo de cada uma das três formas clássicas, evitando o lado negadas três formas clássicas,

Nesse quadro, se a orientação politica geral é dada pelo Executivo, hoje Governo, e pelo Legislativo, ambos eleitos pelo povo, ao Judiciário é dado o papel de freio em defesa da justiça. Po isso, é ele um poder técnico, estruturado de modo a atender às exigências de imparcialidade e in dependência. Os outros são poderes políticos. ele não o deve ser

21. Não é preciso sublinhar o perigo que traz consigo a politização da justiça. Basta lembrar que ela pode vir a sobrepor considerações de oportunidade, ou de conveniência à apreciação objetiva da legalidade, ao reconhecimento e à reparacão do direito individual, mormente fundamental, quando violado. Nunca se deve esé quecer que a suprema garantia da liberdade e um Judiciário independente, como o comprovam séculos de história. A verdade é que o juiz deve servir à justiça, sob pena de desaparecer 0 Estado de Direito.

\section{V - JUDICIALIZAÇÃO E SEPARAÇÃO DOS}

PODERES

22. A análise da Constituição de 1988 exigiu o emprego do termo controle para designar a atividade que, em diversos campos, exerce 0 Judiciário. Há uma razão para isto.

Embora o termo controle tenha entre nós um sentido fraco, vindo do francês contrôle, com a ignificação de fiscalização, verificação - e ceramente foi com este sentido que a doutrina clássica o aplicou a propósito das questões de constitucionalidade - tem ele também um sentido forte, vindo do inglês control, onde transparece a idéia de comando.

Ora, é este sentido forte que espelha o papel dado pela Carta vigente ao Judiciário nos planos examinados.

De fato, se não pode dizer que neles o Judiciário comande positivamente, inegável é reconhecer que ele ai desempenhe um poder negativo, uma espécie de veto absoluto. Fazendo um paralelo com a distinção de Montesquieu entre a faculté de statuer e a faculté d'empêcher no processo legislativo, o Judiciário tem, hoje, nitiprocesso legislativo, o Judiciario tem,
damente, uma faculdade de impedir ${ }^{9}$.

Tal faculdade é intrinsecamente politica. $\mathrm{E}$
a como se assinalou, ela cobre todo o campo do politico, desde o processo eleitoral em que se selecionam os representantes do povo - os governantes - até o exercicio do Poder que se expressa tanto nas leis como nos atos de administraçãa.

23. A transformação do Judiciário em um dos órgãos de controle que devem existir no Es tado contemporâneo, foi há bom tempo antecipada por Karl Loewenstein. Este mostra que a tipologia das funçōes de que se serviu Montesquieu está superada na realidade hodierna. Não, todavia, a idéia de distribuir o seu exercício por 
órgãos separados. A seu ver é necessária uma nova "separação dos poderes" que leve em conta as três tarefas que lhe parecem fundamentais atualmente: a definição da politica (policy decision), a execução da politica (policy execution) e 0 controle da politica (policy control) ${ }^{10}$.

24. Curiosamente, entretanto, o posicionamento do Judiciário na Constituição de 1988 muito se aproxima da versão (clássica) da separação dos poderes presente no Espirito das Leis. Neste, ela tem caráter politico e não juridico. Traduz o ideal do governo misto, procurando equilibrar as relaçōes de poder, por meio de uma divisão em que a atuação politica, ou governamental, dependa de três Poderes que encarnam três forças sociais. $O$ Legislativo pelo qual se exprime o povo (ou seus representantes), o Executivo (o rei), o Judiciário (a magistratura, elite profissional). De fato, no livro de Montesquieu, os três Poderes podem reciprocamente paralisar-se, caso não se disponham a caminhar de concerto ${ }^{11}$.

$\mathrm{Na}$ Carta em vigor, o rei é o Presidente eleito diretamente pelo povo todo que exerce o Executivo; o Legislativo são os representantes dos grupos parciais; o Judiciário, uma elite instruida e não corrompida.

25. Note-se, ademais, que a judicialização biparte a função dos juizes e tribunais. De fato, lado a lado, atuam juizes e tribunais que passam a enfrentar decisōes politicas, e juizes e tribunais que continuam no campo tradicional a dirimir conflitos entre pessoas, a punir criminosos.

Mas, não havendo uma especialização - salvo e dentro de certos limites - são os mesmos individuos que passam de um plano para outro.

Estes juizes, todavia, que são obrigados a se substituir aos administradores ou legisladores, tem a mesma formação e são selécionados pelos critérios tradicionais - salvo nos mais altos tribunais - que os outros, que cuidam de questōes de litigios entre particulares ou sancionam condutas delituosas.

\section{VI - OBSERVAÇÕES FINAIS}

26. O fenômeno da judicialização da politica, nitido no Brasil atual, deve ser encarado com seriedade e estudado com profundidade.
Sem dúvida, é ele devido, sobretudo, à Constituição de 1988 que a impôs ao Judiciário. Não se trata, todavia, de um fenômeno peculiar ao Brasil, ao contrário, por toda parte ele se manifesta. Assim, não parece seja passageiro, facilmente reversivel com uma revisão da Lei Magna. Mesmo porque se apóia nos institutos juridicos na moda entre os juristas mais jovens acão civil pública inconstitucionalidade por omissão, mandado de injunção são para eles temas fascinantes.

Trata-se, porém, de uma questão a merecer aprofundada meditação. De fato, ela modifica muito do caráter do Poder Judiciário. Tem ela assim um profundo impacto sobre a organizacão do Poder que importa numa revisão ou num poderes (pelo menos da visão jurisdicista desta doutrina).

Talvez seja isto inexorável e atenda a exigências inafastáveis do Estado contemporâneo como aponta Lowestein. Mas tem uma contrapartida indesejável, qual seja a politização do Judiciário. Esta não deixa de ser uma ameaça ao Estado de Direito, além de colocar um problema do qual a doutrina foge. Ou seja, a questão da legitimidade democrática do Judiciário e, portanto, a de sua intervenção nos planos legislativo e administrativo da vida governamen tal.

O fenômeno da judicialização da politica não pode, por isso, deixar de ser analisado a fundo para que disto ressaltem todas as suas vantagens e desvantagens. Para tanto este trabalho procurou trazer uma contribuição, ainda que superficial, cuidando essencialmente de salientar seus traços principais e suas linhas fundamentais.

\section{NOTAS DE REFERÊNCIA}

1 No Brasil, esse já foi o tema de artigo que publiquei sob o título "O Poder Judiciário na Constituição de $1988^{\prime \prime}$ (RDA (out-dez 91, mas que circulou em marco de 1995) 198/1). Igualmente, o assunto vem sendo debatido em numerosas oportunidades por autoridades do peso do Ministro da Justiça, o Prof. Nelson Jobim. Foi, outrossim, um dos temas discutidos no IV Encontro de Direito Constitucional (realizado em São Paulo em fins de agosto e início de setembro de 1995), com a participação de eminen- tes jurisconsultos europeus, como o português Cardoso da Costa e o francês Louis Favoreu.

2 Volume 15, no 2, abril de 1994

3 Martin Shapiro, "Juridicialization of Politics in the United States", na International Political Science Review citada, p. 101 e s.

4374 US 4831954

5 Shapiro, art. cit., p. 104

6 Cr. Christine Landfried, "The judicialization of Poltics in Germany", International Political Science Review citada, p. 113 e s.

7 Cf. sempre no citado número da International Political Science Review, Maurice Sunkin, "Judicialization of Politics in the United Kingdom", p. 125 e s.; Barry Holstrom, "The judicialaization of Politics in Swe den", p. 153 e s.; Martin Edelman, "The judicializa on of Politics in Israet,

Art. cit., p. 104.

V. Espirito das Leis, livro XI, cap. VI.

V. Karl Loewenstein, Political power and the govered., 1965 , p. 42 e s.

11 Espirito das Leis, Livro XI, cap. VI.

12 No julgamento criminal do ex-presidente Fernando Collor pelo Supremo Tribunal Federal viu-se bem isto. A revista Veja, no domingo anterior antecipo aspectos do julgamento que só lhe poderiam ter sido dados por quem estivesse "por dentro". Jornais, como o O Estado de $S$. Paulo analisaram a composição do STF em termos proprios para avaliar as correntes de uma câmara partidária.

3 Desse desiderato são significativas as manifestações de inconformismo de alguns juristas com o resultado do julgamento do ex-Presidente Collor pelo Supremo Tribunal Federal. Houve quem ousasse sustentar que a matéria pedia julgamento "político", para atender à "opinião pública", como se o juiz devesse guiar-se pela "voz do povo" (que, na verdade, não passa da "voz da mídia"), sem examinar os autos $\mathrm{e}$ as provas. O cursoso que isto veio do mais rigorosos críticos do "arbitrio" do periodo miitar.

4 Foi Aristóteles o primeiro a encontrar num governo misto a melhor das formas de governo, conquanto chich Cicero no De Republica a repete e desenvolve MonCrevieu inspirou-se nessas licões a louvar a contituiç̃o da Inglaterra, em que se combinam o ele mento monárquico (o Executivo), o elemento democrático (a representacáo popular presente no Legislativo) e 0 aristocrático (a noblesse d'épée na câmara alta do Legislativo; a noblesse de toge, os juizes, guardiãos da Justiça, no Judiciário). 